\title{
"LUGARES DE RESSONÂNCIA" E A PRODUÇÃO DE UMA DIÁSPORA MUSICAL SENEGALESA NO SUL DO BRASIL
}

\author{
"Places of resonance" and the production of a Senegalese \\ musical diaspora in southern Brazil
}

\author{
Kelvin Venturin* \\ Maria Elizabeth Lucas ${ }^{* *}$
}

\begin{abstract}
Resumo. A imigração de senegaleses para o Brasil é parte de um fluxo migratório mais amplo de nacionais de países africanos que se viram atraídos pelas oportunidades de acolhimento que o país oferecia entre 2010 e 2015. Este artigo, oriundo de uma pesquisa etnomusicológica mais ampla entre músicos africanos radicados no sul do Brasil, realizada entre 2018 e 2019, discute a produção de uma diáspora musical senegalesa através das narrativas, trânsitos e colaborações musicais de um rapper senegalês em sua experiência de residência pelo estado. Na esteira de um interesse consolidado na etnomusicologia pelo estudo das múltiplas relações entre música e migração, busca-se explorar a contribuição crítica desses estudos à noção territorializada e fixa da cultura expressiva sonoro-musical. Por este prisma, a etnografia participativa contribuiu para se pensar as práticas musicais migrantes africanas para além das concepções que as associam com uma comunidade étnica coesa.
\end{abstract}

Palavras-chave: etnomusicologia; diáspora; música e migração; senegaleses; Rio Grande do Sul.

\begin{abstract}
Senegalese migration to Brazil is part of a wider migratory flow of nationals from African countries who found themselves attracted by the receptive opportunities that the country offered between 2010 and 2015. This article stems from a broader ethnomusicological research among African musicians settled in southern Brazil, carried out between 2018 and 2019, and it discusses the production of a Senegalese musical diaspora through the narratives, transits and musical collaborations of a Senegalese rapper in his residency experience in the state. In the wake of a consolidated interest in ethnomusicology for the study of the multiple relationships between music and migration, we seek to explore the critical contributions of these studies
\end{abstract}

Doutorando em etnomusicologia no Programa de Pós-Graduação em Música da Universidade Federal do Rio Grande do Sul, com bolsa CNPq. Porto Alegre, RS, Brasil. E-mail: kelvinventurin@ gmail.com. Orcid: https://orcid.org/0000-0003-4950-750X.

** Professora titular na área de Etnomusicologia na Universidade Federal do Rio Grande do Sul. Porto Alegre, RS, Brasil. E-mail: lizabet2008@gmail.com. Orcid: https://orcid.org/0000-0002-4419-3356. 
in relation to notions of expressive sound-music cultures as territorialized and fixed entities. From this perspective, participatory ethnography has contributed to think African migrant musical practices beyond the conceptions that associate them with a cohesive ethnic community.

Keywords: ethnomusicology; diaspora; music and migration; Senegalese; Rio Grande do Sul.

\section{Introdução}

O presente artigo deriva das reflexões de campo elaboradas na dissertação em etnomusicologia "Construindo projetos na mobilidade: práticas musicais e experiência migratória entre senegaleses e ganeses no Rio Grande do Sul"1. A pesquisa de campo realizada entre 2018 e 2019, por um dos autores do presente artigo, procurou aproximar-se de uma rede de relações e colaborações musicais protagonizada por migrantes africanos com vínculos em três cidades do Rio Grande do Sul: Porto Alegre, Passo Fundo e Caxias do Sul. Durante este percurso, o diálogo sistemático com sete músicos/instrumentistas senegaleses e ganeses, com idades entre 30 e 50 anos, acompanhou como esses sujeitos faziam e refaziam seus projetos de vida, suas alianças e como traçavam estratégias de mobilidade e inserção local a partir do seu capital musical vernacular. Valendo-se de uma etnografia da música e dos eventos musicais em sentido amplo (vernaculares, interculturais, globalizados, popizados), modelo idealizado na etnomusicologia nas últimas décadas para abordar as práticas sonoro-musicais em suas complexidades agentivas em determinado espaço-tempo (Lucas, 2013), a dissertação procurou evidenciar como as trajetórias e experiências migratórias particulares desses africanos no extremo sul brasileiro entrelaçavam-se, via mediação musical, com seus processos de inserção em uma sociedade afeita a práticas racistas naturalizadas. No presente artigo, e em diálogo com alguns estudos internacionais da área, os quais vêm teorizando o uso estratégico das músicas vernaculares entre migrantes, focamos um destes eventos de campo, captado pela observação participante e colaborativa em contextos de produção e performance musical migrante, com o intuito de visibilizar as potencialidades deste tipo de estudo interdisciplinar. Antes de entrarmos no foco do presente artigo, situaremos brevemente esta problemática no contexto dos fluxos migratórios recentes para o Brasil.

A imigração de senegaleses para o Brasil está conectada a uma série de ações que colocaram severas restrições à migração, particularmente em destinos geralmente buscados por esses sujeitos, como os Estados Unidos e Europa. Ela é também parte de um fluxo maior de imigrantes vindos da África Ocidental,

Defendida no Programa de Pós-Graduação em Música da Universidade Federal do Rio Grande do Sul, e desenvolvida, com o apoio de bolsa CNPq, no grupo de Estudos Musicais GEM/UFRGS, sob orientação da co-autora. 
atraídos pelas oportunidades que o país oferecia entre 2010 e $2015^{2}$. Essas novas características demográficas, oriundas de uma migração negra para centros urbanos industrializados de regiões hegemonicamente brancas no sul e também sudeste do Brasil, reacenderam discussões sobre racismo estrutural, xenofobia e nacionalismo, no âmbito de um giro político à direita da sociedade brasileira.

Nesse contexto, diversas áreas das ciências humanas passaram a produzir estudos importantes sobre essa diversidade afluente. Parte desse corpus se dedicou a explorar os desafios de inserção no mercado de trabalho (formal e informal) e os constrangimentos enfrentados por muitos desses sujeitos ao tentarem navegar no contexto sociocultural brasileiro (Césaro, Zanini, 2018; Tedesco, 2017; Tedesco, Grzybovski, 2011); ou ainda, estiveram preocupados com as formas estereotipadas e essencializadas como esses migrantes eram representados em veículos de mídia jornalística ou pelo senso comum (Brignol, 2015; Ndiaye, 2020). Outros trabalhos, por sua vez, se concentraram em entender de que forma os migrantes senegaleses no Brasil construíam comunidades de cooperação tecidas por vínculos de pertencimento étnico e religioso, este último ligado às irmandades muçulmanas sufi, as quais se mantinham fortemente conectadas entre si, com o Senegal e a sua diáspora (Gonçalves, Koakoski, 2015; Romero, 2017; Rossa, 2017). Contudo, pelas experiências e observações em campo, como aprendiz na etnomusicologia, surgiu o imperativo de indagar-se: como eram as relações que esses sujeitos forjavam, seguindo a formulação de Young (1986, p. 2) ${ }^{3}$, com quem eles "não estavam em comunidade"? Mais ainda: quais seriam os efeitos dessas trocas do ponto de vista de uma produção cultural emergente em contexto migratório e de interações cruzadas com outros atores sociais fora de seu grupo migrante?

Como aponta Gana Ndiaye (2020), embora a diáspora senegalesa não seja um fenômeno recente e as relações entre Senegal e Brasil e seus nacionais venham desde a década de 1960, ela só ganhou relevância nos discursos acadêmicos brasileiros a partir das ondas migratórias dos últimos dez anos. Segundo o autor, esses estudos, no entanto, ainda não deram conta das diferentes identidades, projetos e noções particulares através das quais senegaleses dão sentido à migração e se posicionam como parte ativa da produção de uma diáspora senegalesa no Brasil (2020, p. 157).

\footnotetext{
2 Segundo Uebel e Ranincheski (2017, p. 83), essa atração se deu em função de uma inserção estratégica do Brasil no cenário internacional. A partir de uma agenda migratória até então nãoexcludente, o Brasil proporcionava condições de moradia, regulamentação e trabalho, ao contrário daqueles países que tradicionalmente recebiam esses fluxos e que, a partir da crise financeira de 2008, passaram a endurecer suas políticas migratórias. Tudo isso enquanto o Brasil ainda vivia um crescimento socioeconômico, pelo menos até 2015, quando passou a enfrentar crises econômicas e políticas.

3 Iris Young (1986) critica o caráter de supressão da diferença evocado pelo ideal de comunidade defendido por teóricos e ativistas radicais ao lidarem com a diversidade. Como alternativa, a autora propõe uma "política da diferença" como forma de pensar as relações sociais de pessoas que vivem juntas em mediação "com quem elas não estão em comunidade".
} 
Neste artigo, partimos dessa lacuna apontada por Ndiaye, para discutir as experiências, trânsitos e colaborações musicais de um rapper senegalês em Porto Alegre, captadas durante o trabalho de campo e que possibilitaram insights novos sobre a produção de uma diáspora musical senegalesa, desta feita no sul do Brasil, a partir do que chamamos de lugares de ressonância, ou seja, espaços de produção musical colaborativa, mediação de diferenças e encontro de comunalidades entre senegaleses, brasileiros e outros grupos migrantes.

Nesse sentido, os usos do conceito de diáspora na etnomusicologia - os quais exploramos a seguir - na esteira de um crescente interesse da disciplina pelo fenômeno da migração dentro dos estudos musicais, contribuíram não só para com a desterritorialização da ideia fixa de cultura (Solomon, 2015, p. 205), mas também para com a flexibilização das noções bastante rígidas de identidade e tradição musical. De fato, a virada pós-estruturalista na etnomusicologia veio impulsionar a observação, a escuta e a reflexão acerca das práticas musicais nos seus diferentes contextos socioculturais, considerando as subjetividades e as experiências pessoais dos sujeitos situados interseccionalmente no espaço/tempo (e.g. Pelinski, 1997; Barz, Cooley, [1991] 2008; Seeger, 2008). Em última instância, nossa experiência participativa em campo mostrou como não é mais possível pensar as práticas musicais migrantes como apenas circunscritas a uma comunidade coesa ou de pertencimento étnico, uma vez que esses sujeitos constroem redes de relações e de colaboração translocais, com múltiplos interlocutores nos novos contextos onde batalham para reorientar suas vidas.

\section{Diáspora na pesquisa etnomusicológica}

Ligado inicialmente às grandes dispersões históricas, o termo diáspora passou a ganhar proeminência no discurso acadêmico em música a partir da década de 1990 (Slobin, 2012, p. 97; Solomon, 2015, p. 201) ${ }^{4}$, sendo em boa parte articulado para referir-se aos sujeitos pós-coloniais e às práticas musicais das diásporas negras: africana, afro-latino-americana e caribenha. Compartilhando fronteiras tênues com outros termos como transnacionalismo e globalização, que também angariaram popularidade nesse período, a diáspora, em termos mais gerais, ganha sua especificidade na dispersão de comunidades ou grupos étnicos pelo mundo os quais mantêm uma certa identidade comum vinculada a sua pátria ou lugar de origem. Transnacionalismo, por sua vez, faz referência às múltiplas redes e fluxos de pessoas, capital e instituições que diluem as fronteiras nacionais, em um mundo cada vez mais conectado pelo avanço das tecnologia de comunicação, informação e transporte, no que convencionamos chamar de globalização (Vertovec, 2009).

\footnotetext{
4 A popularidade do termo no discurso acadêmico mais amplo, porém, vem desde a década de 1960, quando passou a ser usado em referência a diversas formas de dispersão, especialmente nos Estados Unidos, a partir de importantes eventos históricos desse período como o Movimento dos Direitos Civis e a remoção das cotas de imigração que flexibilizaram a entrada de imigrantes de todo o mundo nos Estados Unidos (Reyes, 2019, p. 44; Stankova, 2015, p. 10).
} 
Apesar da etnomusicologia apontar as práticas sonoro-musicais como um importante marcador identitário e étnico de grupos migrantes desde a década de 1970 (Bohlman, 2011, p. 155-156), graças ao incremento de pesquisas interessadas nas "minorias" e em etnografias urbanas (Baily, Collyer, 2006, p. 169), só mais tarde, na esteira de uma mudança contundente de paradigma na disciplina impulsionada pelas discussões pós-modernas de desterritorialização epistemológica (Barz, Cooley, 2008, p. 11-12; Pelinsky, 1997; Slobin, 1994, p. 243), ela iria se engajar no tema da "produção musical diaspórica" ${ }^{5}$. Submetida a uma forte crítica pós-colonial, uma nova geração de pesquisadores confrontados "em tempos e lugares problemáticos", passou a abraçar uma serie de temas relacionados à expressão cultural de musicistas em condições de conflito armado e deslocamentos forçados (Rice, 2014, p. 191), explorando como as questões de identidade, gênero, classe, raça e etnicidade apareciam entrelaçadas nas dinâmicas de eventos/performances musicais e já não mais circunscritos a uma lógica originária e localizada.

Embora conceitualmente distinto, o uso do termo diáspora associado às criações socioculturais e expressivas de grupos migrantes acaba, na prática, se sobrepondo a várias outras categorias que fazem referência ao fenômeno da mobilidade humana (Baily, Collyer, 2006, p. 170). Termos como imigrante, asilado, requerente de asilo, refugiado e exilado apesar de possuírem significados específicos e implicações políticas dentro das legislações dos estados nacionais, os quais têm jurisdição sobre esses sujeitos migrantes, aparecem unidos sob o interesse etnomusicológico em etnografar de que forma comunidades diaspóricas se constituem e lidam com os desafios do deslocamento, ao mesmo tempo em que, através da sua expertise musical, desenvolvem redes culturalmente produtivas e conectadas à sua terra natal e em dialogia com um novo contexto sociocultural.

Em seu artigo "Theorizing Diaspora and Music", Thomas Solomon identifica duas abordagens amplas da diáspora nos estudos musicais: 1) diáspora como formação social e 2) diáspora como metáfora (2015, p. 201). Por "diáspora como formação social", o autor se refere:

(...) àquelas abordagens que enfatizam uma definição sociológica de diáspora e que sublinham os fatos históricos e as condições materiais das diásporas, com investigação empírica focada nas redes sociais que mantêm as comunidades diaspóricas e no papel da música em articular essas redes. (Solomon, 2015, p. 201-202)

Em consonância com Solomon, Thomas Turino, em seu artigo "Identity and the Arts in Diaspora Communities" (2004), parte de uma das primeiras definições programáticas do conceito de diáspora, relacionado a ideia de dispersão de um grupo de pessoas do seus país de origem para vários outros países de destino, feita

5 Para uma revisão consistente desses primeiros estudos ver: Ogut, 2015, p. 274-275; Rice, 2014, p. 197; Slobin, 2012, p. 102; Solomon, 2015, p. 202. 
por Willian Safran (1991), para localizar o conceito de diáspora como um tipo específico de formação social e cultural - diferente de outros grupos migrantes, formações culturais cosmopolitas ou minorias étnicas e raciais. Explora assim como a expressão musical contribui para a formação, manutenção e transformação de uma identidade diaspórica. Para Turino, comunidades migrantes, por exemplo, se diferenciam de formações culturais diaspóricas porque mantêm uma relação bilateral entre o país de origem e o de destino, combinando ambas experiências, enquanto que as diásporas compreendem redes de relações entre vários lugares de destino, que se estabelecem a partir da conexão material ou simbólica com a terra natal (Turino, 2003, p. 59-60).

$\mathrm{Na}$ esteira da popularidade acadêmica do termo, o uso metafórico do conceito de diáspora, como sublinha Solomon, se tornou recorrente na designação de todo tipo de movimento espacial (2015, p. 207). Nos estudos musicais, por exemplo, a ideia de "diásporas musicais" foi usada para se referir aos trânsitos globais que instrumentos, gêneros, estilos e repertórios musicais passam a gozar quando impulsionados pelas tecnologias de reprodução musical e pela cadeia produtiva da música no âmbito das práticas e comodificações, as quais produzem um novo fenômeno de consumo estético designado na mídia global por "World Music" (Feld, 1994, p. 258; Pelinski, 1997, p. 6; Solomon, 2015, p. 208).

Definições como essas, seja pela flexibilização do seu sentido, ou então por uma certa especificidade, nem sempre dão conta das complexidades da mobilidade humana e das subjetividades individuais e coletivas desses sujeitos em um mundo cada vez mais conectado e móvel e fluido. Como escreveu Stuart Hall, a respeito do surgimento ou formação de uma consciência diaspórica na Jamaica, foi só a partir da década de 1970 que uma identidade afro-caribenha se tornou acessível para muitos jamaicanos, através do impacto popular da luta pelos direitos civis nos Estados Unidos, do movimento rastafári e da música reggae, quando então esses sujeitos passaram a também se entender como parte de uma diáspora africana (Hall, 1990, p. 231). Além disso, a forma como as pessoas vivem ou não essa experiência diaspórica e articulam suas identidades através de referências musicais nem sempre se dá no âmbito de uma comunidade étnica coesa ou na participação em redes diaspóricas e transnacionais ${ }^{6}$.

Essas complexidades ficam mais evidentes quando olhamos para o próprio contexto de desenvolvimento do pensamento etnomusicológico, na sua aproximação ao estudo da música em contextos migratórios. Sem dúvida, estes estudos contribuíram para com o rompimento de um nacionalismo metodológico da disciplina representado pela ideia de que a cultura, ou as diferentes "tradições musicais", assim como o estudo das mesmas, derivavam sua autenticidade dos seus

\footnotetext{
${ }_{6}$ É nesse sentido que, neste artigo, articulamos a ideia de "produção" para pensar uma diáspora musical senegalesa a partir dos projetos e ações conscientes de músicos migrantes senegaleses no Brasil.
} 
supostos lugares geográficos de origem, assim como dos grupos étnicos detentores dessas "tradições".

A etnomusicologia, por exemplo, quando se configura como disciplina na década de 1960 nas universidades americanas, carregava todo o peso da herança colonialista no estudo da música dita tradicional, sem registro escrito, associada a lugares específicos, geralmente distantes dos centros acadêmicos, focando seu interesse na descrição estrutural de diferentes gêneros, formas e instrumentos musicais, sem qualquer preocupação em contextualizar processos e pessoas. A crença de que os fluxos migratórios eram temporários e que um futuro retorno desses sujeitos aos seus países deveria ser esperado, fez com que só mais tarde se assumisse que as práticas musicais podiam, sim, ser recriadas, ressignificadas fora do seu contexto nativo. Esses estudos, porém, ao pensar a música em relação a dois contextos diferentes, o lugar de partida e o lugar de chegada, continuavam alinhados com uma noção de autenticidade, buscando medir, nessa dupla dimensão, o quanto determinada tradição musical se mantinha fiel ou não a sua forma "original" (Reyes, 1989, p. 25).

$\mathrm{Na}$ esteira de um maior conhecimento da etnografia urbana, a etnomusicologia nos EUA passou a se preocupar com práticas musicais não circunscritas a grupos étnicos específicos, mas fruto de encontros e trocas em contextos culturalmente heterogêneos nas metrópoles americanas. Nesse sentido, as músicas "transplantadas" pararam de ser pensadas como uma música ameaçada, devido às suas transformações, adaptações e "aculturações" no novo ambiente, e passaram a ser encaradas como uma outra possibilidade, uma outra identidade, uma outra forma musical que não ameaçava a cultura musical em seu contexto nativo (Reyes, 1989, p. 26) .

É no âmbito dessa mesma virada reflexiva que a trajetória do migrante, no que diz respeito aos seus trânsitos desde sua partida, também passa a ser considerada, abandonando a crença de que toda migração era voluntária e todo migrante compartilhava uma rota única e linear entre o "lá" e o "aqui". Nos anos 1990, os estudos da performance musical relacionados à experiência de grupos refugiados trouxeram nuances novas sobre os desafios vivenciados pelas pessoas deslocadas em função de guerras, perseguição política, intolerância religiosa ou desastres naturais. Sobretudo, como esses traumas, violências e múltiplos encontros culturais, como os ocorridos em campos de refugiados em diferentes países (Reyes, 1989), impactavam a reconstrução de suas vidas, assim como de suas práticas musicais e de escuta ao estabelecerem-se em um suposto destino final.

Sem sombra de dúvida, os estudos migratórios e da experiência de refugiados desde a etnomusicologia, contribuíram para com as discussões já candentes na

\footnotetext{
É nesse contexto que muitos estudos buscaram explicar a globalização da música popular de vários países e regiões a partir do conceito de "hibridismo musical", ou seja, como o resultado de uma recombinação de causa-efeito entre elementos técnico-estético-musicais distintos.
} 
antropologia sobre as questões implicadas na representação do "outro", tido como diferente, na esteira de uma crítica ao conceito de cultura como circunscrito a um lugar geográfico específico ou habitando fronteiras nacionais rígidas (Abu-Lughod, 1991; Gupta, Ferguson, 1992). Em seu estudo sobre performances de carnaval, no âmbito da diáspora caribenha na Grã-Bretanha, Tina Ramnarine (2007) vai além para apontar que uma tradição é desenvolvida e transformada em diferentes locais geográficos e por múltiplos indivíduos em sociedades ditas multiculturais, levantando questões problemáticas sobre o nosso compromisso com a etnicidade na investigação musical.

No contexto atual dos estudos sobre música e migração, o conceito de diáspora fornece alternativas analíticas importantes para se pensar as performances musicais nos processos globais contemporâneos e de migrações humanas (Ramnarine, 2007, p. 1-2), ao mesmo tempo em que os pesquisadores têm reconhecido o incontornável caráter contextual (acrescentamos aqui, também relacional) no qual a diáspora precisa ser pensada (Slobin, 2012, p. 97). A seguir, com base nos apontamentos acima, delineamos a ideia de um "rap de conexão", a partir do relato etnográfico de um evento colaborativo junto a um dos nossos interlocutores de pesquisa, como forma de problematizar a produção recente de uma diáspora musical senegalesa no sul do Brasil, assim como de uma estética política na emergência de novas identidades diaspóricas.

\section{"Rap de conexão" e a estética política na produção musical colaborativa de um migrante senegalês em Porto Alegre}

A cena musical da capital senegalesa, Dakar, atravessada por uma ampla rede de rappers, beat makers e estúdios de gravação - muitos deles de construção caseira propiciada pelo avanço e massificação das tecnologias de produção e difusão musical - tem figurado em diversos estudos acadêmicos e na mídia internacional como lócus de uma juventude numerosa e engajada com a cultura hip-hop globalizada (Appert, 2012, 2016; Tang, 2012). Oriundo desse contexto, Ousmane Diaby, um jovem músico, mais conhecido pelo seu nome artístico $\mathrm{Mr}$ Wzeu, migrou para o Brasil em 2013, por volta dos seus 28 anos, através das complicadas rotas transatlânticas que naquela altura eram tomadas por muitos dos seus conterrâneos ${ }^{8}$. Foi na segunda metade de 2018 que travamos conhecimento, apresentados por um amigo senegalês em comum que sabia do meu interesse em pesquisar a atuação de músicos africanos no estado. Logo em seguida passamos a construir uma relação musical colaborativa e a partir dela tive acesso à sua trajetória como migrante e rapper.

\footnotetext{
${ }_{8}$ Por exemplo, via Quito, no Equador, onde não há exigência de um visto para a entrada, e daí seguiam para as regiões metropolitanas do Rio Grande do Sul e São Paulo, por diferentes vias terrestres. Mais detalhes sobre as rotas tomadas por senegales para chegarem ao Brasil, principalmente a partir de 2010, ver Uebel, 2016, p. 59.
} 
Mr Wzeu ingressou na produção do hip-hop em 2004, por volta dos seus 19 anos, quando morava na região dos subúrbios a leste de Dakar. Ao referir-se a eles como ghettos, no jargão comumente utilizado pelos rappers norte-americanos, ou ainda, "favelas", no esforço de traduzir para mim em termos mais localizados as condições dessas regiões, Wzeu conta que fazer rap para ele, e para muitos dos seus pares, significava assumir uma responsabilidade e "ser a voz daqueles que não têm voz", ser aquele que questionava a corrupção política no país e que exigia mudanças unindo, conscientizando e informando os jovens do seu papel político: "a gente falava contra o sistema, sobre política e para valorizar a favela né, o ghetto".

A estética política de um rap "underground", assim chamado por seus autores, produzido em estúdios caseiros nos subúrbios superpopulosos de Dakar e performatizado coletivamente em palcos construídos na rua, teve um papel central no engajamento político dos jovens senegaleses, alguns com acesso ao ensino universitário e à crítica pós-colonial. Através de protestos e incentivando a sociedade senegalesa a votar, desencadearam mudanças significativas no cenário das disputas políticas do país nos últimos vinte anos (Dimé, 2017; Gueye, 2013).

No Brasil, depois de um breve período no qual Wzeu morou em Caxias do Sul, o enrijecimento da fiscalização direcionada à venda ambulante na cidade, sua principal fonte de renda, fez com que ele se radicasse na capital, Porto Alegre. O retorno à produção do hip-hop e a retomada de uma carreia como rapper, porém, viria só mais tarde.

Eu precisava ter mais noção da língua portuguesa porque, como eu estou aqui no Brasil, eu estava ligado que quando eu começasse a fazer o rap eu ia ser convidado para me apresentar e se eu não falasse a língua ia ficar complicado para mim me comunicar. Eu também comecei de novo a minha carreira musical, então eu vou com paciência. Aos poucos as pessoas vão descobrindo o meu trabalho. Lá no Senegal eu tinha um público, só que lá era underground, do ghetto, sabe? Em Diamaguène, tocava cada sábado com um grupo que a gente criou lá no Senegal, eu e mais dois amigos. (Wzeu, comunicação pessoal em: 22/05/2019)

Mesmo tendo continuado a escrever suas letras em wolof ${ }^{10}$, inglês e francês, Wzeu queria fazer um rap condizente com a diversidade que ele enxergava na experiência cotidiana brasileira e dos seus sujeitos - uma realidade da qual ele agora também fazia parte. A ideia de criar, compor um "rap de conexão" entre o Senegal e o Brasil, entre Dakar e Porto Alegre, mas principalmente entre diferentes sujeitos migrantes e brasileiros, precisava ser expressada também em português.

\footnotetext{
${ }_{9}$ Ver, por exemplo, o documentário "African Underground: Democracy in Dakar", produzido pela Nomadic Wax e Sol Productions e filmado antes, durante e depois da eleição presidencial senegalesa de 2007, disponível em: <https://www.youtube.com/watch?v=rLYGQ_PbvUk>. Acesso em: 22.02.2021.

${ }^{10} \mathrm{O}$ wolof é a língua franca no Senegal, sobressaindo-se diante de outras línguas locais, já que a grande maioria dos habitantes em Dakar adotam-na como primeira língua e o francês como segunda.
} 
O necessário aprendizado da língua portuguesa, como um importante capital cultural para navegar o complicado e desigual contexto da sociedade brasileira, se deu de forma autônoma; embora a formação em Letras pela Universidade Cheikh Anta Diop, de Dakar, não lhe tenha garantido emprego e condições suficientes para permanecer no Senegal, ela Ihe havia proporcionado ferramentas necessárias para superar o desafio do aprendizado de uma língua estrangeira.

Figura 1 - Mr Wzeu. Captura de tela do videoclipe "Senegal"

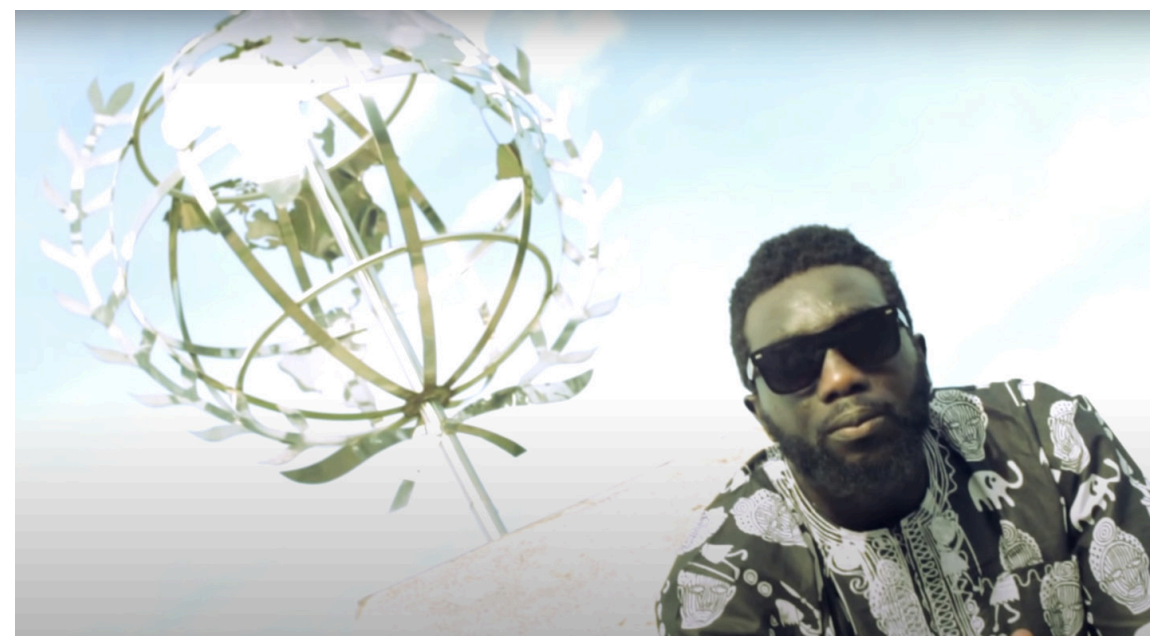

Em Porto Alegre, o chamado centro histórico da cidade, além de um importante espaço de comércio e de venda informal para muitos brasileiros e senegaleses, foi o lugar onde Wzeu conheceu uma série de sujeitos que, em paralelo às suas ocupações diárias (estudo e trabalho), buscavam construir as suas carreiras no hip-hop. Centrais a essa rede estavam Aj04, D'Lokc e LeeJay, três jovens negros, moradores na periferia da zona sul da cidade, que haviam montado um estúdio caseiro nos fundos da casa de um deles para produzirem as suas próprias músicas. Nesse mesmo espaço, fundaram a gravadora OnRecordz para atender aos pedidos de produção e gravação dos trabalhos musicais de outros artistas do bairro e regiões da cidade. Como Aj04 explica:

Nós começamos no hip-hop, produzindo nossos raps, mas aqui no estúdio nós trabalhamos com música em geral. Na verdade... porque através do rap eu consigo conversar com vários outros gêneros musicais. (Aj04, comunicação pessoal em: 29/11/2018)

Aj04 se refere aqui ao que a etnomusicóloga Catherine Appert, em seu estudo sobre a produção de hip-hop em Dakar nos anos 2000, chama de "intertextualidades na produção do hip-hop", ou seja, sua própria forma estética, 
depende de práticas de sampling ${ }^{11}$, citações e diálogos intertextuais com outros artistas, práticas musicais e temporalidades (2012, p. 15). Appert explora em sua etnografia como, através desses processos, jovens rappers reescreviam a diáspora na África e a África na diáspora, seja para afirmarem que o rap sempre foi senegalês, fruto de tradições locais que resistiram - sem deixar de se reinventar - à migração forçada até as Américas, e que agora faziam o seu retorno à África, seja para entendê-lo como um produto das lutas socioeconômicas e raciais de culturas afro-diaspóricas nos Estados Unidos.

Parte da diáspora musical senegalesa no sul brasileiro era, portanto, produzida a partir de encontros como esse, com Aj04, e em estúdios caseiros como o dele, vistos como espaços de colaboração e trocas musicais, mediação de diferenças e identificação de comunalidades entre senegaleses, brasileiros e outros grupos de migrantes. Era a partir desses lugares de ressonância que Wzeu construía uma identidade musical e expressiva como rapper senegalês no Brasil.

Os estudos da diáspora e migração, como já referidos anteriormente neste artigo, contribuíram não só para a flexibilização das noções até então territorializadas de cultura e de produção cultural. Eles agregaram novas ideias sobre como as identidades (representações seletivas de si mesmo) e as subjetividades (sentidos de si mesmo) são constructos fluidos, múltiplos e em constante transformação pelas experiências vividas, ao contrário da forma homogênea e essencializada em um só lugar e grupo social específico, como eram entendidas anteriormente (Turino, 2004, p. 8-9).

Nesse caminho de afirmação do papel da subjetividade como instrumento de conhecimento, foi importante seguir as relações intersubjetivas entre os sujeitos de pesquisa e o pesquisador, em seus contextos e condições sociais específicas de enunciação como são a praxe no trabalho de campo; ou ainda, no âmbito da pesquisa sobre migração, como mostram os estudos etnomusicológicos de Ramnarine, com as performances de carnaval em Londres (2007), e o de Reyes, em dois campos de refugiados vietnamitas nas Filipinas (1989), sobre as relações e as trocas de aprendizagens musicais que os diferentes sujeitos e grupos migrantes mantêm entre si e com os distintos indivíduos e grupos nas sociedades receptoras e de trânsito.

Como aponta Turino, as identidades - "fruto das interações entre sujeitos particulares e suas condições objetivas, que ao mesmo tempo são individuais e coletivas" - dizem respeito tanto às diferenciações que as pessoas e grupos fazem entre si, quanto ao reconhecimento das suas similaridades (Turino, 2004, p. 8).

\footnotetext{
11 Viabilizado pelas novas tecnologias de manipulação sonora - hardwares/softwares musicais, instrumentos musicais digitais - o sampling reutiliza uma amostra (sample) de um som previamente gravado - algum ritmo ou batida (beat), uma melodia, uma fala, ou outros sons - para criar outra obra/produto digital, valendo-se de técnicas digitais de edição e manipulação sonora dessa amostra prévia.
} 
Ser músico, estar envolvido com a produção do hip-hop e interessado em suas intertextualidades, narrativas genealógicas e conexões diaspóricas transatlânticas ${ }^{12}$, ser negro em uma sociedade estruturalmente racista como a brasileira, se tornavam, por exemplo, pontos importantes de estabelecimento e sustentação de relações musicais colaborativas em campo. Como sugerem Baily e Collyer, a música entre migrantes possui uma conexão profunda e emocional com a memória e com a construção de novas identidades individuais e de grupo (2016, p. 173). Nesse sentido, a produção de uma diáspora musical senegalesa no Brasil acontecia também a partir das experiências que os sujeitos que aparentemente "não estavam em comunidade", compartilhavam em comum e que reverberavam em suas trajetórias particulares.

Minha entrada como estudante universitário branco nesses lugares de ressonância e de colaboração musical, se deu através dos próprios processos de produção e performance do hip-hop nesse meio. "Fazer um feat."13, participando e colaborando em um dos raps de Wzeu, foi a frequência que encontramos para construir uma relação colaborativa que ressoasse para ambos, ele, com sua carreira no rap e projeto mais amplo de produção de um "rap de conexão", e eu com a minha pesquisa acadêmica sobre encontros musicais entre migrantes africanos no extremo sul do Brasil. Embora eu, baterista, percussionista e aprendiz de etnomusicólogo via temática das migrações, estivesse um tanto distante de ser considerado um rapper, nos reconhecíamos como músicos e interessados em fazer música. Foi dessa forma que pude estar, ao mesmo tempo, em campo e envolvido nas dinâmicas de produção que aconteciam no estúdio de gravações da OnRecordz, na zona sul de Porto Alegre.

Wzeu e o produtor Aj04 haviam produzido anteriormente o videoclipe "Xippil Sa Beut" (Abre o olho), seu primeiro trabalho no Brasil. No estúdio, a familiaridade entre eles rendia conversas sobre o trabalho de rappers internacionais, sobre raps que fizeram sucesso e referências de "batidas" que gostavam de incluir na produção de um "beat"14. Em certas ocasiões, as sugestões e pedidos de Wzeu colocavam Aj04 em um terreno confortável, como em relação ao uso de samples e à criação de "batidas" ligadas ao funk brasileiro. Em outras, nem tanto, quando se tratava do uso de amostras de ritmos, instrumentos musicais e melodias de países da África Ocidental. Wzeu, então, geralmente contatava amigos em estúdios de Dakar, parte de suas redes de relações transnacionais, que colaboravam com Aj04

${ }^{12}$ O conceito de "Atlântico negro", do historiador Paul Gilroy (1993), ajuda apontar as múltiplas identidades e experiências diaspóricas negras das américas e neste caso específico, as suas interconexões através do hip-hop.

13 "Feat" é a abreviação do termo em inglês "featuring", usado como gíria na produção musical do hip-hop para fazer referência à participação especial de um outro artista em determinada música de um grupo ou rapper solo. No Brasil essa expressão costuma aparecer como "participação" ou abreviada como "part.".

14 Batida, ou beat, para os interlocutores da pesquisa, era sinônimo da construção rítmica de um rap ou então do conjunto das faixas instrumentais de uma música. 
na produção desse beat, o qual ia se transformando a partir da escuta de Wzeu de cada nova versão recebida.

Minha colaboração nessa produção musical em estúdio consistiu em cantar o refrão na remixagem ${ }^{15}$ de "Canto para o Senegal". Lançada pela banda baiana Reflexu's na década de 1980, grupo ícone da axé music ${ }^{16}$ que veio mais tarde extrapolar as fronteiras do país, Wzeu buscava, com essa escolha, fazer uma homenagem à banda - popularizada no Senegal através dessa canção - que também era reproduzida com frequência pelos meus interlocutores senegaleses no Rio Grande do Sul como forma de materializar essa conexão histórica. Atos performativos que me sinalizavam um desejo de marcar os laços afetivos entre Brasil e Senegal que haviam sido tecidos musicalmente pelo grupo baiano trinta anos antes.

Intitulado "Senegal", Wzeu dividiu o remix em duas partes. Na primeira delas, as rimas em wolof, francês e inglês faziam referência aos valores éticos, morais, laborais que do ponto de vista do ethos religioso muçulmano representam o Senegal como nação. Ao mesmo tempo, evidenciavam a importância pessoal de se manter conectado a essa pátria e leal a esses valores de respeito, honestidade, solidariedade e resiliência com os quais cresceu, diante dos enfrentamentos e das provações impostas pelos deslocamentos como migrante.

[...]

$\begin{array}{ll}\text { Choose the right way } & \text { [escolha o caminho certo] } \\ \text { Never cry "mayday" } & \text { [nunca chore por ajuda] } \\ \text { Do your job every day } & \text { [faça o seu trabalho todo dia] } \\ \text { Real man back in the day. } & \text { [homem verdadeiro daquele tempo] }\end{array}$

As rimas em português de Wzeu, na segunda parte do remix, aludiam à dura realidade enfrentada por muitos senegaleses e pelos migrantes no Brasil e na diáspora senegalesa pelo mundo, positivando essa busca por uma vida melhor, ao mesmo tempo em que a narrativa construía uma identidade diaspórica própria como rapper, trabalhador migrante senegalês e negro na sociedade brasileira.

\footnotetext{
Orgulho ser negro, preto, guerreiro

Com a cabeça bem feita.

Vencedor, lutador, trabalhador, conquistador.

Hey rapaziada, não fica parada,

Levanta na madrugada,

Buscar uma vida melhor, faz parte dos melhores.

$[\ldots]$
}

\footnotetext{
${ }^{15}$ Remixagem se refere a ação, popularizada pelos DJs e produtores musicais a partir da década de 1970, de modificar músicas previamente conhecidas a partir da edição e adição de trechos rítmicos, melódicos ou vocais para criar novos trabalhos.

${ }^{16}$ Trata-se de um gênero de música popular gerado culturalmente na cidade de Salvador, BA, na década de 1980, pela articulação performática de vários ritmos afro-diaspóricos.
} 
Em etapa posterior, a produção de estúdio passou pelo desafio de virar um videoclipe que seria gravado em lugares considerados por Wzeu emblemáticos da cidade onde, como migrante, batalhava a sua projeção como artista ${ }^{17}$. Posicionados em cena de rua, eu, o "feat.", e os demais participantes convidados, ouvíamos a música já finalizada soar repetidas vezes de uma pequena caixa de som portátil. A tecnologia auxiliava Wzeu em suas coordenadas de nos guiar na performance a céu aberto, ao mesmo tempo em que nos deixava livres para nos movimentarmos da forma como achássemos melhor, interagindo com as batidas da música; no meu caso, buscava também pistas nos movimentos de meus companheiros de "palco". Os sons e timbres sintetizados na abertura da canção em ritmo de reggae - gênero musical emblemático da diáspora negra nas Américas - introduziam uma breve citação da guitarra elétrica da canção original, editada por Aj. Indicando para que eu me coloca-se na frente deles, Wzeu me posicionava em evidência para cantar reiteradamente o bordão: "Sene, senê, senê, senê, Senegal!".

Wzeu havia mantido no refrão a articulação da palavra "Senegal" para a qual fui incumbido de elaborar uma linha melódica vocal. Mesmo receoso em assumir tamanha visibilidade logo no início do videoclipe, segui as coordenadas. Afinal de contas, fui designado como feat. dessa performance e parte importante da construção sonora e visual dessa conexão, como sujeito branco entre migrantes negros defrontando-se com o contexto racista no extremo sul do país. Com a paleta de cores que emergia dos corpos dançantes, suas vestimentas com estampas estilizadas de times de futebol ou em tecidos africanos, dos acessórios e das bandeiras brasileira e senegalesa completava-se a articulação de uma política comunicacional desse "rap de conexão".

Tão importante quanto os processos de gravação, edição e mixagem dessas sonoridades em estúdio, foram, portanto, a performance musical live e coletiva de "Senegal", bem como a captação de imagens locais para a composição do videoclipe que acompanhava sua produção musical ${ }^{18}$. Em locais cuidadosamente escolhidos, geralmente ao ar livre, onde as paisagens da cidade se tornavam elementos importantes de registro cultural do estrangeiro, Wzeu convergia na performance sua rede de relações e experiências locais: jovens brasileiros ligados à dança de rua, a percussão e dança de um grupo de migrantes ganeses de Acra, companheiros da venda ambulante, o pesquisador interessado no rap senegalês migrante. Era através da multiplicidade de signos visuais, das combinações sonoras, tímbricas, corpóreas inscritas no videoclipe, que Wzeu reescrevia a sua África na diáspora e a diáspora em seus raps, comunicando através de imagens

\footnotetext{
17 Disponível em: <https://www.youtube.com/watch?v=P46xvEApNO0>. Acesso em: 13.02.2021.

${ }^{18}$ É preciso citar aqui a produtora audiovisual Selo Verde, principal parceira da OnRecordz nesse quesito.
} 
e imaginários seus encontros musicais como rapper senegalês em experiência migrante no Brasil ${ }^{19}$.

Lançada nas várias plataformas de streaming e redes sociais online, o vídeo alcançou um número considerável de visualizações no Youtube, o que lhe rendeu convites de entrevistas e a participação em um programa local de TV. Além de circular pelas redes e grupos de WhatsApp de senegaleses no Brasil e alhures, o videoclipe foi publicado pelo site de notícias senegalês "Senego" ${ }^{20}$ onde, segundo Wzeu, já é de praxe a divulgação dos trabalhos culturais de imigrantes na diáspora. Se por um lado o fazer musical the ofereceu oportunidade de mobilidade local, por outro, pude perceber os constrangimentos, desafios comunicacionais e tentativas de Wzeu de desconstruir estereótipos, recorrendo ao seu capital intelectual e formativo universitário, quando, por exemplo, as entrevistas que lhe faziam eram geralmente guiadas por imaginários brasileiros bastante essencializados sobre a África.

Conforme argumentou Bohlman, a migração é sempre política na sua busca por melhores oportunidades no exterior e no exercício de inserção desses sujeitos em sociedades estrangeiras. Nesse sentido, as práticas expressivas, como a música e seus discursos, que emanam dessa mobilidade são, para o autor, eminentemente politizadas (Bohlman, 2011, p. 151). É nesse mesmo sentido interpretativo que o conceito de "práxis sonora", desenvolvido pelo etnomusicólogo Samuel Araújo a partir da inserção em contextos atravessados pela violência nas periferias do Rio de Janeiro, sustenta o terreno da performance musical como sendo de ação política, pois propõe alianças, mediações e rupturas diante do controle do Estado ou das micropolíticas que regem o cotidiano de grupos e indivíduos (Araújo, Paz, 2011, p. 211).

Como apontam Baily e Collyer, a produção musical migrante não está necessariamente direcionada para dentro de uma comunidade migrante, na manutenção de uma identidade de grupo. Ela muitas vezes leva à criação de novas formas de expressão musical que são indicativas e sintomáticas das subjetivações, dos enfrentamentos, encontros e desencontros dos migrantes. Direcionadas para "fora", tendo como alvo uma comunidade mais ampla, elas articulam novas identidades individuais e de grupo aos olhos e ouvidos dos "outros" (2006, p. 174-175).

${ }^{19}$ Parte dos processos e dinâmicas desses lugares de ressonância podem ser vistos com um pouco mais de detalhes em uma espécie de cena extra ou making off deixado ao final desse videoclipe (3min42s). Contendo trechos de tomadas que, de outra forma, não estariam na edição final do vídeo, essa foi a alternativa encontrada por Wzeu de incorporar essas imagens de interação que considerou valiosas. Nessas cenas, o som da percussão, ausente na música produzida em estúdio, acompanhava os movimentos de dança que eram ensaiados/experimentados/performados e ao mesmo tempo registrados pelas câmeras dos celulares dos participantes, assim como momentos de descontração e "alegria", esta sugerida por Wzeu como mote principal para o que deveríamos buscar expressar na performance.

${ }^{20}$ Disponível em: <https://senego.com/video-ce-clip-fait-le-buzz-au-bresil_844969.html>. Acesso em: 29.04.2021. 
A dimensão política de um "rap de conexão" parece transcender as criações musicais de Wzeu. Ela se dava nas relações colaborativas que ele estabelecia desde esses lugares de ressonância e "práxis sonora", seja em estúdios de gravação, sets de filmagem ou ainda nos espaços ocupados pela venda ambulante na cidade, onde essas novas expressividades migrantes também emergiam.

Da mesma forma como a ficção científica pavimenta o caminho para o avanço da ciência, diferentes formas de produção cultural, atravessadas pelos desafios e contextos da modernidade tecnológica, mobilidade humana e globalização, sugerem novos imaginários, identidades e pertencimentos (Turino, 2004, p. 11). Em seus videoclipes, Wzeu projetava futuros possíveis, não ingênuos, de integração na diferença e de novas identidades diaspóricas emergentes a partir da performance da diversidade musical.

Figura 2 - Captura de tela do videoclipe "Senegal"

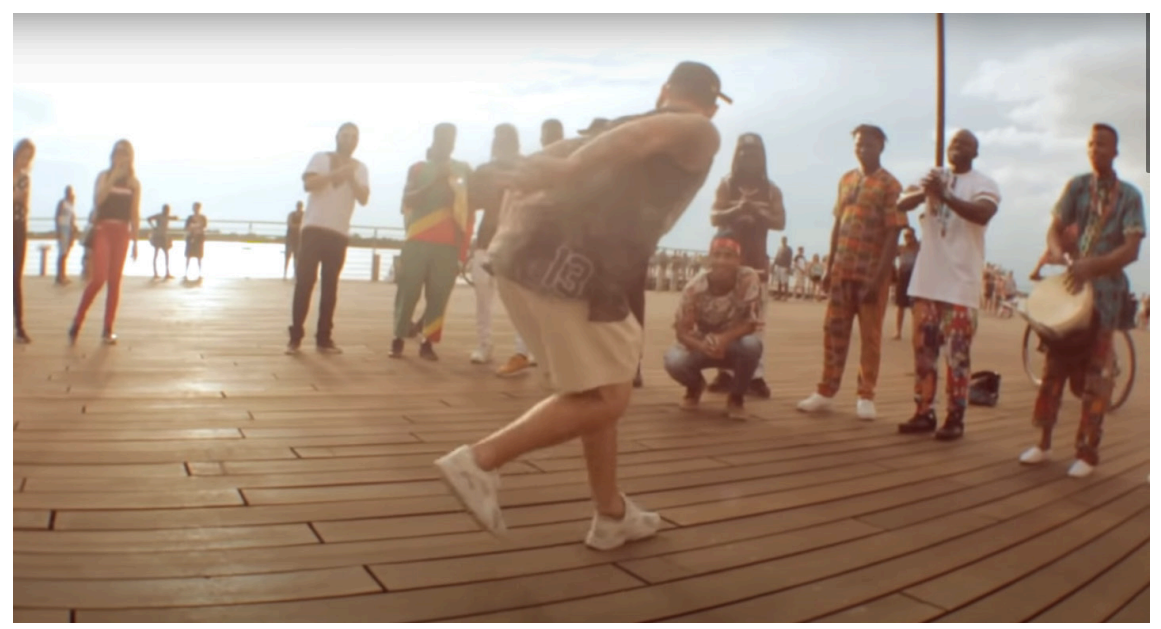

\section{Considerações finais}

Neste artigo, exploramos as contribuições que um estudo etnomusicológico focado nos eventos de performance musical, em contextos migrantes, pode oferecer para reposicionar noções fixas de "identidades" e "tradições musicais". Através das produções musicais colaborativas de um rapper senegalês radicado em Porto Alegre, buscamos sugerir outras perspectivas de estudo sobre a emergência de novas identidades diaspóricas, no caso, pela via da produção de uma diáspora musical senegalesa no sul do Brasil.

O contexto pandêmico de 2020, juntamente com as medidas de isolamento social, evidentemente impactaram esses lugares de ressonância dos quais tratamos neste artigo. Por outro lado, o ambiente das redes sociais online e plataformas digitais sempre foram o meio principal de veiculação dessas produções musicais. 
Dessa forma, Wzeu se manteve resiliente na produção de um "rap de conexão", aproveitando a maior presença online das pessoas para divulgar seus videoclipes. Outros, por sua vez, buscaram fortalecer as suas alianças, migrando com esses espaços de ressonância para o ambiente online, onde oferecem suas aulas, oficinas e performances musicais de forma virtual.

Por fim, em consonância com a tese levantada pelos estudos etnomusicológicos da importância do capital musical na inserção dos sujeitos e grupos migrantes em sociedades estrangeiras, buscamos contribuir com a reflexão sobre as nuances com que os migrantes dão sentido próprio à migração, posicionando-se como parte ativa da produção de uma diáspora musical senegalesa no Brasil a partir dos seus projetos, alianças e colaborações musicais.

\section{Referências bibliográficas}

ABU-LUGHOD, Lila. Writing Against Culture. In: FOX, Richard G. (ed.). Recapturing Anthropology: Working in the Present. Santa Fe: School of American Research Press, 1991, p. 137-162.

APPERT, Catherine M. Modernity, Remixed: Music as Memory in Rap Galsen. PhD Dissertation. UCLA, 2012. Disponível em: <https://escholarship.org/uc/ item/67p2t96w > . Acesso em: 28.04.2021.

APPERT, Catherine M. On Hybridity in African Popular Music: The Case of Senegalese Hip Hop. Ethnomusicology, v. 60, n. 2, p. 279-299, Spring/Summer 2016.

ARAÚJO, Samuel; PAZ, G. Leal. Música, linguagem e política: repensando o papel de uma práxis sonora. Terceira Margem, Rio de Janeiro, v. 25, p. 211-231, 2011.

BAILY, John; COLLYER, Michael. Introduction: Music and Migration. Journal of Ethnic and Migration Studies, v. 32, n. 2, p. 167-182, 2006.

BARZ, Gregory F.; COOLEY, Timothy J. (eds.). Shadows in the Field: New Perspectives for Fieldwork in Ethnomusicology. 2 ed. New York: Oxford University Press, 2008.

BOHLMAN, Philip V. When Migration Ends, When Music Ceases. Music and Arts in Action, v. 3, n. 3, p. 148-165, 2011.

BRIGNOL, Liliana Dutra. Senegaleses na mídia: representações de novos fluxos migratórios para o Rio Grande do Sul. In: ALAIC - Revista latino-americana de ciencias de la comunicación, v. 12, n. 22, p. 70-81, enero/junio 2015.

DE CÉSARO, Filipe Seefeldt; ZANINI, Maria Catarina Chitolina. "Tem que estar bonito pra vender": a produção senegalesa de espaços de venda em Santa Maria (Rio Grande do Sul, Brasil). REMHU, Revista Interdisciplinar da Mobilidade Humana, Brasília, v. 26, n. 52, p. 95-110, Abr. 2018.

DIMÉ, Mamadou. De bul faale à Y'en a marre: continuités et dissonances dans les dynamiques de contestation sociopolitique et d'affirmation citoyenne chez les jeunes au Sénégal. Afrique et développement, v. XLII, n. 2, p. 83-105, 2017.

FELD, Steven. From schizophonia to schismogenesis: the discourses and practices of "world music" and "world Beat". In: KEIL, Charles; FELD, Steven. Music Grooves, Essays and Dialogues. Chicago: University of Chicago Press, 1994, p. 257-289. 
GILROY, Paul. The Black Atlantic. Harvard University Press, 1993.

GONÇALVES, Maria C.; KOAKOSKI, Yan C. "Salaam Aleikum": o aspecto religioso na dinâmica migratória dos senegaleses para Caxias do Sul. In: HERÉDIA, Vania Beatriz Melotti (org.). Migrações Internacionais: o caso dos senegaleses no sul do Brasil. Caxias do Sul: RS: Belas-Letras, 2015, p. 239-261.

GUEYE, Marame. Urban Guerrilla Poetry: The Movement Y'en a Marre and the SocioPolitical Influence of Hip Hop in Senegal. Journal of Pan African Studies, v. 6, n. 3, p. 22-42, September 2013.

GUPTA, Akhil; FERGUSON, James. Beyond "Culture": Space, Identity, and the Politics of Difference. Cultural Anthropology, v. 7, n. 1, p. 6-23, 1992.

HALL, Stuart. Cultural Identity and Diaspora. In: RUTHERFORD, Jonathan (ed.). Identity: Community, Culture, Difference. London: Lawrence \& Wishart, 1990, p. 222-237.

LUCAS, Maria Elizabeth (org.). Mixagens em campo: etnomusicologia, performance e diversidade musical. Porto Alegre: Marcavisual, 2013.

NDIAYE, Gana. Mobility and Cultural Citizenship: The Making of a Senegalese Diaspora in Multiethnic Brazil. In: MEERZON, Yana; DEAN, David; MCNEIL, Daniel (eds.). Migration and Stereotypes in Performance and Culture. Contemporary Performance InterActions. London: Palgrave Macmillan, 2020, p. 157-177.

OGUT, Evrim Hikmet. Transit Migration: an unnoticed area in ethnomusicology. Urban People, v. 17, n. 2, p. 269-282, 2015.

PELINSKI, Ramon. La etnomusicologia en la edad posmoderna. 1997. Disponível em: <http://www.candela.scd.cl/docs/pelinski.htm>. Acesso em: 09.04.2021.

RAMNARINE, Tina K. Musical Performance in the Diaspora: Introduction. Ethnomusicology Forum, v. 16, n. 1, p. 1-17, Jun. 2007.

REYES, Adelaida. From Native to Adopted Land through the Refugee Experience. Yearbook for Traditional Music, v. 21, p. 25-35, 1989.

REYES, Adelaida. The Beneficence and the Tyranny of Paradigms: Kuhn, Ethnomusicology and Migration. In: HEMETEK, Ursula; KÖLBL, Marko; SAĞLAM, H. (eds.). Ethnomusicology Matters: Influencing Social and Political Realities. Viena: Böhlau Verlag GmbH \& Co. KG, 2019, p. 33-52.

RICE, Timothy. Ethnomusicology in Times of Trouble. Yearbook for Traditional Music, v. 46, p. 191-209, 2014.

ROMERO, Fanny. Islã, parentesco e ritual na irmandade religiosa Mouridiyya: percursos da etnografia no contexto da imigração de africanos senegaleses no Brasil. In: TEDESCO, João Carlos; KLEIDERMACHER, Gisele (org.). A imigração senegalesa no Brasil e na Argentina: múltiplos olhares. Porto Alegre: EST Edições, 2017, p. 275-296.

ROSSA, Juliana. Poética vocal religiosa de imigrantes senegaleses mourides em Caxias do Sul-RS. In: TEDESCO, João Carlos; KLEIDERMACHER, Gisele (org.). A imigração senegalesa no Brasil e na Argentina: múltiplos olhares. Porto Alegre: EST Edições, 2017, p. 297-309. 
SAFRAN, William. Diasporas in Modern Societies: Myths of Homeland and Return. Diaspora, v. 1, n. 1, p. 83-99, 1991.

SEEGER, Anthony. Etnografia da Música. Cadernos de campo, São Paulo, n. 17, p. 237260, 2008.

SLOBIN, Mark. The Destiny of "Diaspora" in Ethnomusicology. In: CLAYTON, Martin; HERBERT, Trevor; MIDDLETON, Richard (eds.). The cultural study of music: a critical introduction. 2nd ed. New York: Routledge and Taylor \& Francis Group, 2012, p. 96-106.

SOLOMON, Thomas. Theorizing Diaspora and Music. Urban People, v. 17, n. 2, p. 201-219, 2015.

STANKOVA, Maria. Diaspora, Transnationalism, Globalism, Oh My! academic discourse and use. SEM\{studentnews\}, v. 10, p. 10-11, 2015.

TANG, Patricia. The Rapper as Modern Griot: Reclaiming Ancient Traditions. In: CHARRY, Eric (ed.). Hip Hop Africa: New African Music in a Globalizing World. Bloomington: Indiana University Press, 2012, p. 79-91.

TEDESCO, João Carlos. "Em nome de ...": religião, trabalho e mercado. Senegaleses em frigoríficos do centro-norte do Rio Grande do Sul. In: TEDESCO, João Carlos; KLEIDERMACHER, Gisele (org.). A imigração senegalesa no Brasil e na Argentina: múltiplos olhares. Porto Alegre: EST Edições, 2017, p. 311-338.

TEDESCO, João Carlos; GRZYBOVSKI, Denise. Senegaleses no Norte do Rio Grande do Sul: integração cultural, trabalho e dinâmica migratória internacional. REP Revista Espaço Pedagógico, v. 18, n. 2, Passo Fundo, p. 336-355, jul/dez, 2011.

TURINO, Thomas. Are we global yet? Globalist discourse, cultural formations and the study of Zimbabwean popular music. British Journal of Ethnomusicology, v. 12, n. 2, p. 51-79, 2003.

TURINO, Thomas. Introduction: Identity and the Arts in Diaspora Communities. In: TURINO, Thomas; JAMES, Lea (eds.). Identity and the Arts in Diaspora Communities. Warren, MI: Harmonie Park Press, 2004, p. 3-19.

UEBEL, Roberto R. G. Panorama e perfil da imigração senegalesa no Rio Grande do Sul no início do Século XXI. Boletim Geográfico do Rio Grande do Sul, Porto Alegre, n. 28, p. 56-77, set. 2016.

UEBEL, Roberto R. G.; RANINCHESKI, Sonia. Pontes ou muros? As diferentes ações dos governos de Lula da Silva, Dilma Rousseff e Michel Temer em relação às migrações internacionais para o território brasileiro. OIKOS, Rio de Janeiro, v. 16, n. 2, p. 79100, 2017.

VERTOVEC, Steven. Transnationalism. London: Routledge, 2009.

YOUNG, Iris Marion. The Ideal of Community and the Politics of Difference. Social Theory and Practice, v. 12, n. 1, p. 1-26, Spring 1986. 